\title{
The Intelligence of Complexity: Do the Ethical Aims of Research and Intervention in Education Not Lead Us to a New Discourse "On the Study Methods of our Time"?
}

\author{
JEAN-LOUIS LE MOIGNE \\ Université d'Aix Marseille III (France)
}

\begin{abstract}
To better appreciate the contribution of the 'paradigm of complexity' in Educational sciences, this paper proposes a framework discussing its cultural and historical roots. First, it focuses on Giambattista Vico's (1668-1744) critique of René Descartes' method (1637), contrasting Cartesian's principles (evidence, disjunction, linear causality and enumeration), with the open rationality of the 'ingenium' (capacity to establish relationships and contextualize). Acknowledging the teleological character of scientific inquiry (Bachelard) and the inseparability between 'subject' and 'object', the second part of the text explores the relevance of 'designo' (intentional design) implemented by Leonardo da Vinci (1453-1519) in order to identify and formulate problems encountered by researchers. Referring to contemporary epistemologists (Bachelard, Valery, Simon, Morin), this contribution finally questions the relationships between the 'ingenio' (pragmatic intelligence), the 'designo' (modeling method) and ethics. It proposes one to conceive the paradigm of complexity through the relationships it establishes between (pragmatic) action, (epistemic) reflection and meditation (ethics).
\end{abstract}

Because the Cartesian Method undermines ingenium and ingenium was given to human beings in order to understand, that is, to act intentionally...

- Giambattista Vico (1710/1993, p. 136)

"A new paradigm for 'lifelong' educational policies" ${ }^{1}$ : With such a challenge Teresa Ambrósio (2006) invited us last year to assume our civic responsibilities - both individually and collectively - towards "restoring all the solidarities among all the phenomena"2 (Bachelard, 1934, pp. 10-11, my translation) we continuously face throughout our life:

${ }^{1}$ See the wonderful article "Chemins de Formation: Inscrire dans la société les chemins de l'autoorganisation, de l'autonomie et de l'identité" with which Teresa Ambrósio concluded the work she directed with Frédérique Lerbet-Sereni (Ambrósio \& Lerbet-Sereni, 2006).

${ }^{2}$ Terms used by Bachelard in order to express the ideal of complexity of contemporary science. 
Acquiring an open rationality, taking into account the imaginary dimension of 'governance', vivifying opportunities for dialogism, for the recreation of meaning, for the permanent revaluation of communities' historical and durable convictions (values), which is required by the changes of our times and by the new worldwide problems we have been tackling. (ibid.)

Do these few lines not characterize the core of what might be expected from this new epistemological paradigm? As early as 1934, Bachelard had already identified this "new scientific spirit" by inscribing it in the heart of a non-Cartesian epistemology ${ }^{3}$. By that time, to define a new paradigm by the negative was somewhat disturbing. Yet, reading it today, we are benefiting from the multiple constructive developments that have been occurring since then, so well synthesized and notably documented in the six volumes of Edgar Morin's (1977-2004/2008) La Méthode 4 . From now on, let us consider this nonCartesian epistemology - which brings us back to "the ideal of complexity of contemporary science" (Bachelard, 1934) - as the epistemology of complexity. Doing so we can exert our intelligence of complexity without having to previously reduce it, in conformity with the methodological prescriptions of the four principles of Descartes' method (Descartes, 1637).

During the last three centuries, Descartes' imperative methodological prescriptions rapidly assumed an ethical value. They claimed the correspondence between 'criteria of scientificity' (scientific logic and objectivity) - held as unique and exclusive -, 'truth value' and therefore 'moral rectitude'. It is worth remarking that the Port Royal Logic (Logic or the art of thinking) (Arnaud \& Nicole, 1684/1992) - which justifies Cartesian precepts based on Aristotle's axioms of perfect syllogism - was made the European teachers' basic manual for two centuries. Thereafter, what was assumed as 'scientifically true' became what was considered with certainty as 'morally good' in our cultures. At the same time, ethics was no longer considered as the object of individual and collective deliberation; it was considered as a necessary result of some kind of perfect syllogistic reasoning (independent of the subject who reasons). In our schools, we are still suffering from some residual effects of this form of scientism, that Comte's "Positivist' catechism" (1852) and Boole's "Laws of Thought" (1854/2005) would somehow make sacred in teaching, if not in cultures. The disappearance of both 'rhetoric' and 'topics' from almost all European school programs in the early 1900's contributed to officialize this symbolic exclusion of ethical deliberation and argumentation from the educational systems.

Such perverse effects, which are better diagnosed today, raised the awareness of researchers and practitioners who - from 1950 onwards - exerted their own epistemological criticism ${ }^{5}$. Their brave efforts enable us today, as responsible citizens in solidarity, to challenge the ethical and epistemological legitimacy of practices and research in educational sciences.

Based on their contributions, it is now possible to describe and unfold the paradigm of complexity in all its features, which are carefully argued in the form of an alternative paradigm solidly built and epistemologically legitimated. The traditional paradigm yesterday prevailing in our academies and so frequently known as Cartesian-positivist can thus be defined by contrast as the paradigm of complication (epistemologists usually prefer to name it "paradigm of reductionism"). As it is not necessary to reproduce here a description of both paradigms, figure 1 summarizes them schematically, displaying side

\footnotetext{
${ }^{3}$ Title of the last chapter of "Le nouvel esprit scientifique" (Bachelard, 1934).

${ }^{4}$ See also Morin's (2001) book "Seven complex lessons in education for the future" commissioned by the UNESCO and specifically dedicated to the educational components of Morin's paradigm of complexity.

${ }^{5}$ In the second half of the $20^{\text {th }}$ century, in French speaking cultures, I have to name at least Jean Piaget, Yves Barel and Edgar Morin.
} 
by side the epistemic (I) and methodological (II) concepts each paradigm privileges in its own development.

In order to be able to fruitfully understand the paradigm of complexity in its contemporaneous cultural matrix, what is needed - I think - is to restitute its cultural roots. Doing so, we can only benefit from the astonishing cognitive experience formed and transformed through this human adventure, which is simultaneously the adventure of human knowledge: "True newness always springs up when one returns to one's roots" as Morin (1997, p. 49, my translation) reminds us. The paradigm of complexity (and constructivist epistemologies) did not emerge in the early 1950 as a 'fully armed Athena'. Its teachable and practicable three-millenary heritage is at least as rich (and not less pertinent) as the one claimed by Cartesian-positivist paradigms, still prevalent in the culture of our academic institutions. A discussion around the contributions of Giambattista Vico (1668 - 1744) and Leonardo da Vinci (1453 - 1519) might also allow us to adopt those other lenses that can enrich and stimulate practitioners', teachers' or researchers' intelligence.

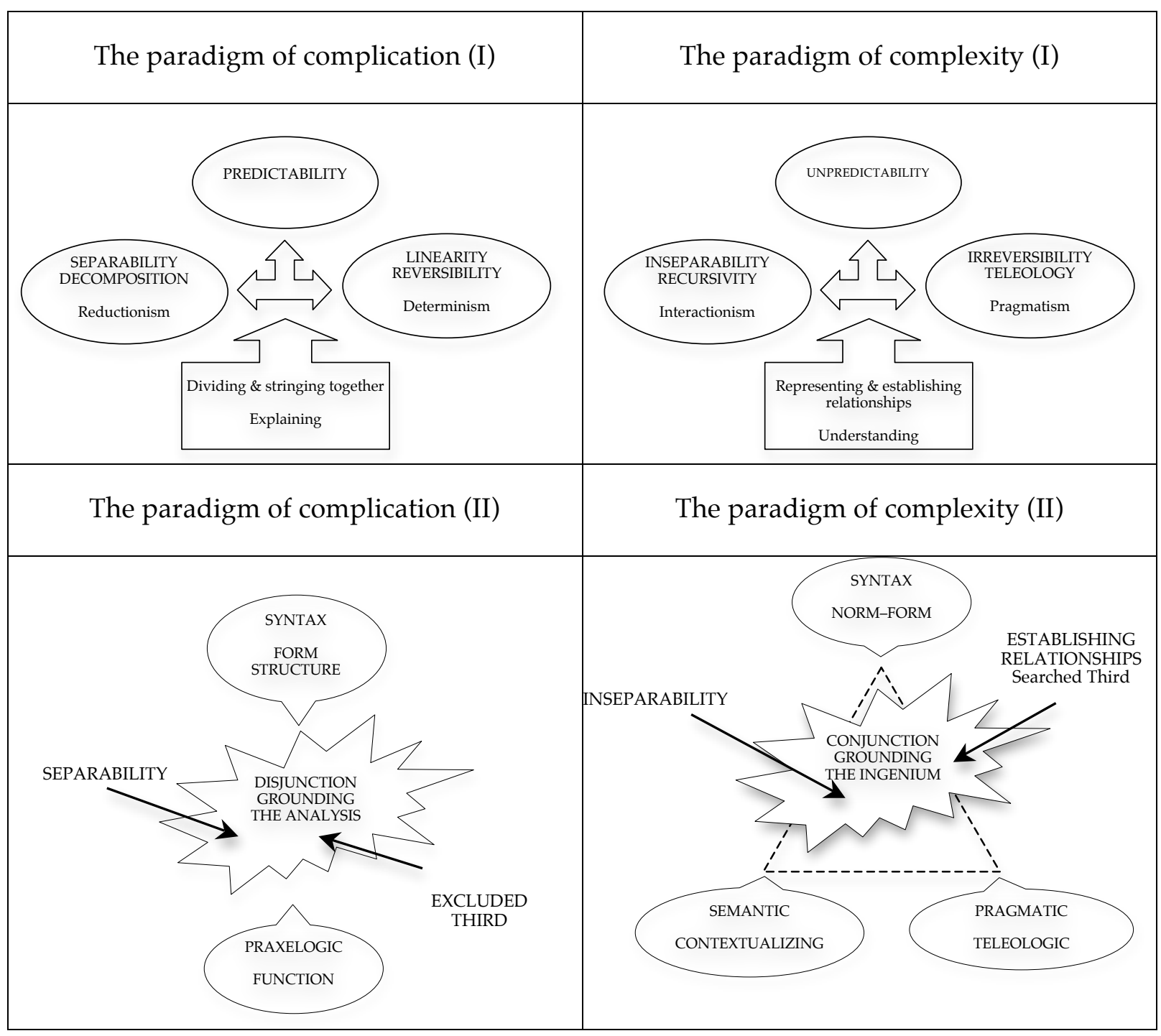

Figure 1: Two epistemological paradigms 


\section{Back to the "Discourse on the study method of our time"}

We often forget, especially in French-speaking cultures - which are proud of their Cartesian legacy $^{6}$ - that from 1708 onwards (when it was disseminated throughout all European universities) this discourse became the object of a critical, though constructive, discussion fostered by a professor from the University of Naples (Italy), Giambattista Vico. This discussion was invested with a relative solemnity at that time, considering it was the opening discourse of the 1708 academic year and was addressed to all civilian and academic authorities of the Realm of Naples, and to the students as well. Uttered in Latin - as it was traditionally the custom - it has been published shortly afterwards and thereafter quoted in its original title "De nostri temporis studiorum ratione". This title was properly translated into French as "La méthode des études de notre temps" ("On the study methods of our time"), a title that values the particularly up-to-date resonance of our times, as Alain Pons so fairly highlights?

In this text, indeed, Vico wonders about the direction studies, and therefore thought in general, had been taking in Europe, since Descartes and those who claim his legacy, imposed a kind of intellectual dictatorship. Claiming to extend to all knowledge fields the method of geometric analysis, Cartesianism drove young people away from the tradition of rhetoric humanism and tried to repress among them everything that stems from the field of sensitiveness, memory and imagination, i.e. youth's prevailing faculties. As Vico wrote it in a letter dated from 1729, it filled their head with "mouthful words like 'demonstrations', 'evidences', 'proven truths', thus preparing them to enter a men's world made of lines, numbers and algebraic signs"... (Pons, 2005, p.4)

To this abstract and dry Cartesian world, threatened by what he will call later in his "New Science" (1744) the "barbarity of reflection", Vico opposes the real human world, in its richness and complexity, the world created and "invented" by human beings themselves - creation and invention which rely upon all their faculties, particularly upon ingenium, which is not a simple tool for deduction, but rather an inexhaustible source of innovation. In this sense, one understands well why current constructivist epistemologists claim Vico's legacy, considering the fact that they represent attempts to look for methods and paradigms that allow one to restitute the complexity of reality, in a better way than positivist epistemologies do since Descartes. (ibid.)

When reading Vico's pages - written three centuries ago - we understand better Teresa Ambrósio's invitation to develop "a new paradigm for 'lifelong' educational policies". Is it not first a matter of acquiring an open rationality?

In order to briefly illustrate this argument, it is relevant to compare side-by-side the Cartesian principles with those formulated by Vico. At the opposite of Descartes, Vico did not try to progress from tabula rasa; he rather tried to benefit from the contributions of both his contemporaries (whether René Descartes or Francis Bacon", "a man of incomparable wisdom", he would say) and masters from the Greco-Latin tradition (from Aristotle to Cicero).

\footnotetext{
6 "Discourse on method" was originally published in French, which was not a usual practice in 1637 for this kind of treaty.

${ }^{7}$ As his translation from 1981 was completely out of print, Alain Pons permitted the site Réseau Intelligence de la Complexité (RIC) to publish the full text of his translation and presentation in RIC's series "Les Classiques". Available at: www.intelligencecomplexite.org/docs/conseilscient/0511vico_pons.pdf. Alain Pons introduced this re-edition in a short preface from which these lines have been extracted.

8 "Novum Organum" emerges in 1620, shortly before Cartesian discourse (1637). Vico stresses one of its main formulas: "What is sought after is invented and judged by a single and same operation of mind" (Bacon, 2008, p. 140, my translation).
} 


\section{The principle of evidence, a criterion of truth?}

Vico's core argument is the "criterion of truth", that human beings can all reasonably and mutually recognize: what is true is what we can effectively do. Verum et Factum, "the true is the made". The argument is a call for intellectual humility and, above all, it brings humans to consider their great moral responsibility. It is not because we can pragmatically make the true that we can ethically make the good. The two-way correspondence claimed by Cartesianism, between the scientifically true and the morally good, is a priori arbitrary, and there is no 'high priest' (even of the "positivist religion") who holds the true truth, unique and liable to be imposed to every human beings. The 'criterion of truth' imposed by the first of the Cartesian principles - the one claiming the universal evidence of what is clear and distinct in our spirit - does not manifestly carry any imperative evidence. Let us compare the texts:

\begin{tabular}{|c|c|}
\hline Evidence by clarity (Descartes) & Relevance by feasibility (Vico) \\
\hline $\begin{array}{l}\text { "The first [evidence] is to never accept as } \\
\text { true what cannot be evidently recognized as } \\
\text { such, which means carefully avoiding haste } \\
\text { and anticipation and incorporating in my } \\
\text { mind anything more than what is so clearly } \\
\text { and so distinctly presented to my mind that I } \\
\text { would never have the opportunity to put } \\
\text { into doubt [italics added]." (Descartes, 1637, } \\
\text { pp. 19-20, my translation) }\end{array}$ & $\begin{array}{l}\text { "From what has been previously said, it can be } \\
\text { concluded that the criterion of truth, and the rule } \\
\text { required in order to recognize it, is to have made it; } \\
\text { Consequently, the clear and distinct idea we have of } \\
\text { our mind is not a criterion of truth, not even a } \\
\text { criterion of our mind; because by knowing itself, } \\
\text { the mind does not make itself, therefore, as it } \\
\text { does not make itself, it is not aware of the way it } \\
\text { knows itself... [italics added]" (Vico, 1710/1993, } \\
\text { my translation) }\end{array}$ \\
\hline
\end{tabular}

The principle of disjunction, a methodological principle?

Challenging the metaphysical criterion of teachable and practicable truth (whether following Plato or theology) does not lead to resignation. Instead of looking for the perfection of the analytical syllogism - splitting and mutilating knowledge - it suggests us, very pragmatically, to unfold the superb range of human reason. Descartes formulated a formula, which became almost sacred as "scientific analysis" or reductionism of method, considered during two centuries, as being consubstantial with science. Vico became rapidly aware of the cognitive impoverishment brought by this exclusive supremacy of division and disjunction. His aim was therefore to open up the range of human reason through the exploration of innumerable masterworks produced by human minds dedicated to the exercise of their ingenium - this strange faculty of mind characterized by the capacity to establish relationships (relier). 


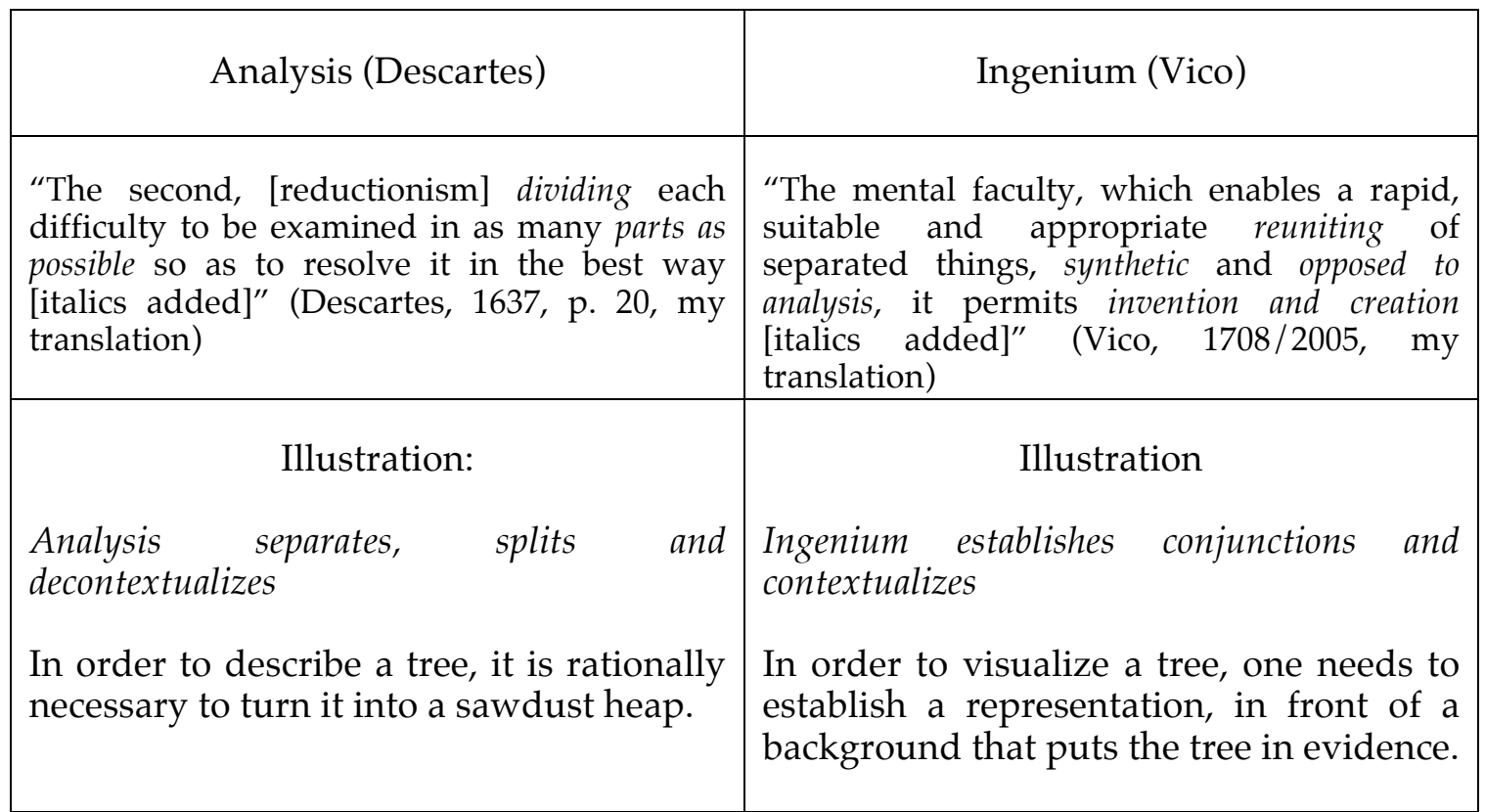

From "De ratione" (Vico, 1708/2005) to "Scienza nuova" (Vico, 1744/1997), the complete works of Vico can be presented, as a masterly illustration of the power of the ingenium - or culture of the ingenium, as Floris (1974) wrote - in the production and study of human knowledge. From Greeks' Métis (or the "shrewdness of intelligence") to Edgar Morin's "complex thought" and Herbert Simon's "procedural rationality", we regularly find in the adventure of human knowledge the same features characterizing the pragmatic uses of reason. We find the same awareness of the challenges (paris) raised by any decision; the same critical capacity to exert deliberation as well - and often better - than practicing demonstration. For Vico, the acknowledgment of the creative power inherent to the faculty of reuniting (relier) - aiming to understand through contextualization, rather than reduce to an explanation - should be positioned at the core of the study of our time.

I quote with pleasure here some lines from the "Essays in Tektology" written by Bogdanov (1981, p. 64) ${ }^{9}$ - the still hardly known pioneer of systemic modeling, a Russian researcher from the beginning of the twentieth century, who deserves much greater attention. These lines highlight the universal character of the supremacy of conjunction in human experience. "Conjunction comes first":

It has been established for a long time that in his practical or cognitive activities, human beings can do only two things: unite or separate.

However, further investigations show that these two actions, junction and disjunction, do not play an equal role in human activities: one of these functions, the act of joining, conjunction, comes first, the other one is always derived and resulting from it, the act of separation, disjunction. In cognition as elsewhere.

Uniting first means therefore 'intentionally contextualize': I do not think there is a better way to define ingenium's role and operating mode.

\footnotetext{
${ }^{9}$ The original manuscript in Russian and German was edited in 1921, but it was completely censured during Russian Stalinist times.
} 


\section{The principle of linear causality, a determining criterion?}

The exercise of ingenium is not restricted to an exercise of spatial contextualization (the representation of a tree in its context here and now); very spontaneously, the human mind conceives multiple temporal conjunctions. Memorization is at the centre of human cognitive activity. Floris (1974, my translation) also highlighted this facet of the activity of ingenium, brought back to our culture by Vico.

For F. Bacon memory, imagination and reason were ordered according to a hierarchical scale of values; reason being at the top. With Vico the order is broken by ingenium, which becomes the polarizing centre for memory and imagination.

Conjunctions among processes are at least as important as conjunctions among the forms which are stable enough to be recorded by a snapshot. Nobody can 'freeze' a wave breaking on the shore, nevertheless anyone is able to intelligibly describe it. It brings to mind the dream of Mr. Palomar so perfectly described by Calvino (1985) ${ }^{10}$. At the same time irreversible and recursive, the ongoing breaking of the wave cannot be conceived through a trivial mode of apprehension, based on long chains of simple reasons, which would flow linearly. Such long 'chains of simple reasons' would claim that the movement of a wave never affects the movement of the following waves and is never affected by the breaking of the previous ones. There is no evidence legitimating such a claim. Why should it be imposed in order to reason well?

Aren't we able to reason well when we see the recursive conjunction of the end to the means and of the means to the end? When Leonardo da Vinci drew the formation of whirlpools and the opposing currents that form a watercourse, was he not proposing a judicious measure in order to interpret these recursive phenomena, which today are known as the 'hydrodynamics of non-linear phenomena'? Irreversibly, when functioning, the phenomenon considered is transformed, and being transformed, it functions differently. The subsequent wave, like the one before, transforms the functioning of the wave that Mr. Palomar (ibid.) tried to immobilize when he was observing it on the shore. Therefore, rather than invoking a determining reason imposing a decisive, unique, universal end, couldn't the human mind exercise its ingenium, its reflective and pragmatic (or groping) reason, and apply it to the intentional (or critical) exploration of the field of possibilities that opens up in front of us?

\begin{tabular}{|c|c|}
\hline Linear causalism (Descartes) & Intelligent pragmatism (Vico) \\
\hline $\begin{array}{l}\text { "The third, following the order of my thoughts, } \\
\text { beginning with the simplest objects and the } \\
\text { more accessible to know, to climb slowly, step } \\
\text { by step, to the most compound ones, and } \\
\text { presuming order even between those that are in } \\
\text { no way precedent on one another. } \\
\text { These long chains of very simple and easy } \\
\text { reasons, that geometricians are in the habit of } \\
\text { using to reach their most difficult } \\
\text { demonstrations, had given me the } \\
\text { opportunity to imagine that all the things that } \\
\text { can fall within the jurisdiction of men's knowledge } \\
\text { follow each others in the same way [italics } \\
\text { added]" (Descartes, 1637, p. 20, my } \\
\text { translation) }\end{array}$ & $\begin{array}{l}\text { "As if one did not see caprice, the fortuitous, } \\
\text { opportunity, and chance, ruling in human } \\
\text { things, looking for walking straight through the } \\
\text { anfractuosities of life, looking for following the } \\
\text { method of geometricians in a political discourse, } \\
\text { means that one does not use any ingenium, [it } \\
\text { means that] one says nothing about what can } \\
\text { be found under one's steps, [it means] } \\
\text { treating one's listeners like children to whom } \\
\text { food is not given without first being } \\
\text { masticated [italics added]" } \\
\text { (Vico, 1710, my translation) } \\
\text { "The order of ideas should follow the order of } \\
\text { things [italics added]" (Vico, 1744/1997, 44, } \\
\text { 238). }\end{array}$ \\
\hline
\end{tabular}

${ }^{10}$ This text serves as an exergue to Lerbet-Sereni's (2004) book. 
"Above the subject, beyond the immediate object, modern science is grounded in the project. In scientific thought, the meditation of the object by the subject always takes the form of a project" Bachelard's (1934, p. 15, my translation). Bachelard's famous formula invites us to recognize the teleological character of the intelligent exercise of human reason. It requires one to assume the recursive inseparability of the interactions of the subject and the object, successively observed and observer. In other words, it requires one to continuously make explicit the projects or the points of view through which we can, when we are acting, understand our actions.

To illustrate this argument, it is relevant to quote some lines from Morin's "Method" (1977/1992, pp. 176-178), taken from a paragraph titled "the problem of the conceiver".

The problem of the observer/conceiver - must we already say, of the subject? - appears to us here and now as capital, critical, decisive ... Let us take the swirl: we must isolate it in its own existence and organization, but we must also situate it in the river, of which it is part, which is itself a part of a wild machine cycle. We can isolate the flame of a candle, a very beautiful small motor, wild in its nudity, civilized in its regularity: this wild motor exists only in terms of the civilized candle, and the set flame/candle constitutes a small polysystem; whereas individually the flame is an open system as energy and the candle a closed system, together they constitute something else, multiple and ambiguous, where the candle can appear as the energy reserve of the flame system, where the flame can be conceived as the process of disintegration of the candle system, where the candle can be conceived as a small machine to produce light which is part of the anthrop-social megamachine ... Now, in each of these examples, we see that the description of the machine changes, and sometimes radically, depending on whether we change the point of view changes.

Whence the problem of the observer/describer/conceiver: he must have a method which allows him to conceive the multiplicity of points of view, then pass from one point of view to the next; he must have theoretical concepts which, instead of closing and isolating entities (physical, biological, sociological), allow them to circulate productively ... In fact, the developments of praxic complexity... is therefore necessary; it respects the complexity of reality and develops the complexity of thought.

The observer must not only practice a method which allows him to pass from one point of view to the next ... he also needs a method to accede to the meta-point of view on the diverse points of view, including his own point of view as subject inscribed and rooted in a society. The conceiver is in a paradoxical situation ...

It is no longer the concept born of $17^{\text {th }}$ and $18^{\text {th }}$ century mechanistic thought, nor is it that of Wienerian cybernetics. It is a regraded concept, no longer degrading the being or the existent to which it is applied. It revolutionizes the previous notion of machine. This new concept, instead of hiding the great problems and mysteries, poses them necessarily.

No wonder then that the exercise of ingenium (contrarily to analysis through linear chains) has to do with our capacity to identify these various points of view, according to which we can represent and interpret the phenomena we consider to be in the flame's action: from the candle to the classroom or to the organization of a journey. Isn't this what Ambrósio (Ambrósio \& Lerbet Sereni, 2006) reminded us of when inviting us to acquire an open rationality?

\section{The Principle of Enumeration, a hypocritical criterion?}

Here, I purposefully propose to contrast the fourth and last hypocritical principle of the Cartesian discourse with an almost official recommendation recently proposed by the French CNRS (Centre National de la Recherche Scientifique, 2002) instead of one of Vico's developments on the topical-critical method. The aim here is to highlight the topicality of the "Discourse on the study methods of our time" (Vico, 1708/2005). 


\begin{tabular}{|l|l|}
\hline The principle of enumeration (Descartes) & $\begin{array}{l}\text { The principle of the projective opening } \\
\text { (Vico) }\end{array}$ \\
\hline $\begin{array}{l}\text { "And the last [principle]: to make such } \\
\text { remplete enumerations and such general } \\
\text { of omitting nothing [italics added]" } \\
\text { (Descartes, 1637, p. 20, my translation) }\end{array}$ & $\begin{array}{l}\text { "Binding oneself to complexity, ... involves the } \\
\text { point of view on the real, from which a ordering } \\
\text { work, partial and continually adaptable, can be } \\
\text { carried out ... From this perspective, the } \\
\text { exploration of complexity appears as the project } \\
\text { of maintaining open permanently, it the work of } \\
\text { scientific explanation itself, the recognition of } \\
\text { the role of unpredictability [italics added]" } \\
\text { (Centre National de la Recherche Scientifique, } \\
\text { 2002, my translation) }\end{array}$ \\
\hline
\end{tabular}

This CNRS document was supposed to constitute CNRS researchers' epistemic-civic reference; unfortunately most of them still ignore it, not easily admitting the recognition of the dimension of unpredictability, linked to teachable and practicable scientific knowledge. This document added:

Only taking into consideration the 'interactions between the elements' is no longer sufficient. It is required to develop new instruments of thought [I add: some of those are often rather old, as illustrated by Vico's texts], which allow the appropriation of the phenomena of retroaction, recursive logics, situations of relative autonomy... It is a real challenge for knowledge, from an empirical and a theoretical point of view as well. (Centre National de la Recherche Scientifique, 2002, p. 13, my translation)

This is the challenge to empirical and theoretical knowledge that the author of "Scienza Nuova" incited us to accept three centuries ago, when he was exercising his ingenium on the history of the complex formation of the "wisdom of the nations"... or of "common sense". As a distinguished contemporary reader of Vico, Luglio (2003, pp. 107-111) proposes to keep "topical-critical method at the service of scientific reconstruction". Developing a concept of "topics" as an epistemological instrument, Vico restores the energy of the "topics" illuminated by the flame of the "critique". Thus he invites us to pragmatically assume the complexity of any method of scientific research: "But if we covered all the places of topics with the flame of critique, then we would be certain to recognize the object ... proposed ... And in this successive examination even topics is critical" (Vico, 1710/1993, p. 125, my translation).

This brief exploration of one of the sources of the call for the restoration of the paradigm of "open rationality" (giving life to places within which to practice dialogics, recreate meaning, continuously reevaluate sustainable and historical convictions) enriches the project of a collective effort to reopen the "Discourse on the study methods of our time". It suggests the exercise of the resources of ingenium and it brings one to understand the changes of our time and the new worldwide problems with which we are confronted, that is, to exercise our intelligence of complexity. Shouldn't researchers and practitioners in Educational sciences be among the pioneers of the epistemic work this task requires today? These questions are as ethical ones, as they are pragmatic ones. 


\section{On the power of "disegno" for the intelligence of complexity}

The second principle of the Cartesian discourse (Descartes, 1637, p. 20, my translation) positioning the almost exclusive need for analysis ("dividing each difficulty to be examined in as many parts as possible") as the utmost virtue of any teachable science ("everything that can fall within the jurisdiction of human knowledge") - had an effect, which was identified much later. The facts (données) constitutive of the problems that humans have to negotiate are a priori held as data by the analytical method (whence the name in French "donnée", which curiously translates the Latin "datum"). Moreover, though implicitly, this method is presumed to be unique and independent of the subject who uses it. Precious postulate for all teachers since they all should do nothing but teach the good methods of resolution or calculation of the problems given to the students, providing them a priori with the facts (données) constitutive of these problems... which are precisely those to which such presumable data can be applied.

The teaching situations and collective actions, where the origins of these data is revealed and criticized remain however quite rare. However, anyone knows that those facts, which are accepted as 'data', in order to become facts have to be made. Such data represent what has been made (more than facts). They had to be built or modeled, taking the form of systems of artificial symbols. Bachelard (1938, p. 14, my translation) reminds us of this from the very first pages of "La formation de l'esprit scientifique":

And, whatever is said, in scientific life, problems are not formulated by themselves. It is precisely the meaning [sens] of the problem that leaves the mark of the truly scientific mind. For a scientific mind, any knowledge is an answer to a question. Without a question, there can be no scientific knowledge. Nothing can be taken for granted [rien de va de soi]. Nothing is given. Everything is built.

It seems therefore legitimate to wonder about the methods of identification and formulation of the problems, implemented by scientific researchers, who were not yet familiar with the Descartes' (1637) principles ("rightly conducting one's reason and [for] seeking truth in the sciences"). Vico would gladly quote here Bacon's (1620) "Novum Organum": "What is sought, through the same operation of mind, is what is invented and what is judged" (Bacon, 2008, p. 140, my translation); that is what is represented (or modeled) and what is interpreted (or understood). Human ingenium does not function in a different way when it describes and when it interprets. More recently, Simon repeated in 1989 to an audience of computer programmers who were not caring enough about the elaboration of the data they were treating through sophisticated algorithms: "'Modeling' is neither more nor less logical than 'reasoning'" (Simon \& Kaplan, 1989).

It is, I believe, in the 6000 pages of the manuscripts of Leonardo da Vinci's "Notebooks" that we will find an explanatory reply to this question, which should always comes first: how can we intentionally model the phenomena we are interested in? We know that the scientific work of da Vinci is manifestly notable and is concerned with practically every field of knowledge, natural and life sciences, sciences of the universe and engineering sciences. But it is not emphasized enough that it was produced before 1519 by a self-taught person who had worked 150 years before the diffusion of the Cartesian "Discourse on Method". Reading the pages of the "Notebooks", we have the privilege to reach a thought in progress and in transformation: we see the thought at the work as much as we see the finished work. When Valéry read da Vinci's "Notebooks" in 1894, he emphasized it very well (see his "Introduction à la Méthode de Léonard da Vinci", Valéry, 1894/1919).

Thanks to the work of historians of art and science, we have a better understanding today of the key concept used by da Vinci in order to characterize this modeling method: the "disegno", which in brief means intentional design. Here it is necessary to translate this Italian word, admirably presented not so long ago in its historical context by Ciaravino 
$(2004)^{11}$. If da Vinci was not the inventor of the disegno it was certainly he who most admirably emphasized its cognitive power.

In order to restore the symbolic status of this sixth sense, revealed by the disegno in our all too Cartesian cultures, Ciaravino brings us to explore deeply and passionately the texts, which mark out the construction and the recognition of the notion of disegno in Renaissance Italy - a "complex context characterizing a cultural revival, that considers visual arts from a scientific point of view" (Ciaravino, 2004, p. 15, my translation). Since its origin, this word designates "... a means of expression located between practice and theory" (ibid., p. 17, my translation). But this instrument will rapidly "exceed what prolongs or reinforces human's action. In the strongest and most literal sense of the term, it is the 'incarnation of the mind, the materialization of thought' as A. Koyré would write" (ibid., p. 18, my translation).

The disegno will then become "the place where the fundamental functions of communication and expression are released... through an increasingly intense process of symbolization: representing an idea by a figure, which participates to the universality and the idealization of its object" (Klein, quoted in Ciaravino, 2004, p. 111, my translation). We enter into a fascinating adventure, that we are still experiencing today:

"It is the concept of reality itself, which is challenged: Man [sic] finds himself on earth interacting with the nature he interprets, judges, represents at the same time that he rediscovers it. In relation with this explicative system about the world, the disegno is developed following the pre-established analogy between the macrocosm and the microcosm, the universal and the singular, but also as a vision always in process, which expresses the effort made in order to truly understand this correspondence, beyond the recognition of its existence. The disegno belongs to the order of activity, of the potential production of images... But nothing prevents us from seeing it according to the explicative scheme retained to explain the symbol. As a visible form taken by the idea, the disegno can become a vehicle for thought... what is stronger in this renewed conception of disegno is the fact that its intellectual value is no longer exclusively metaphysical, but more intrinsically, it becomes part of the order of its own materiality, as if the mind needed, in order to be, a support for its intelligibility" (ibid., p. 112, my translation)

We cannot prolong here this meditation on the interweaving between pragmatics and episteme inspired by the disegno; a meditation we can easily continue today, reassured in some way by the symbolic legitimacy of its birth in human cultures - those of the Quattrocento - Quintocento's Renaissance - which did not apprehend as much as we do today the paradoxes of knowledge, whether those of art or post-Cartesian science.

It is undoubtedly in da Vinci's writings that we can find the richest perception of disegno's intelligence of complexity. Ciaravino (1987) dedicates an excellent chapter to da Vinci's meditations on the disegno in his "Notebooks". The title of this chapter is one of da Vinci's formulas ${ }^{12}$, which I think constitutes the most emblematic motto of complex system modeling.

The disegno is of such an excellence that it not only shows the works of nature, but it also produces infinitely more varied forms. And therefore, we conclude that it is not only a science. (Ciaravino, $1987, \S 20$, pp. 89-90, my translation)

...It goes beyond nature because nature's elementary forms are limited; the works that human vision requires from human hands are unlimited. (Ciaravino, 1987, § 74, p. 152, my translation)

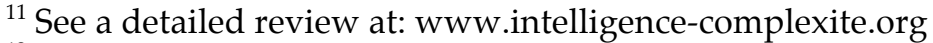

${ }^{12}$ A formula that had been already emphasized by Kemp (1987, p.131) on da Vinci's work, in the catalogue of the exhibition titled "Leonard da Vinci, Ingénieur et Architecte" which was held in 1987 at the Musée des Beaux Arts de Montréal.
} 
This restoration of the concept of disegno to our cultures continues nowadays little by little. As an example, we can cite Basbous' essay (2005) "Avant l'œuvre, essai sur l'invention architecturale" whose main chapter is entitled "Le pari du disegno". This author indirectly proposes a good definition of what we mean when we present the 'method of systemic modeling', conceiving phenomena according to their projects perceived in their context.

The notion of disegno evokes simultaneously a movement of thought, its direction, as well as the representation in which it is recognized. This ambivalence between intention [dessein] and design [dessin], which will disappear from the French language during the Enlightenment, gives a semantic richness to the Disegno, providing it the right to enter the pantheon of fundamental notions ... The disegno is shaped [prend forme] through a narrow complicity between the thought that doubtfully proposes, the eye that witnesses the quality of relationships and initiates the displacement of lines, and the hand that accompanies and maintain the smallest movements of the mind (Basbous, 2005, p. 13, my translation).

\section{What would be the worth of 'a study method' that does not call for an 'exercise of ethical meditation'?}

And what would be the worth of an ethical reflection that would not call for an exercise of "internal epistemological criticism" (Piaget, 1967, p. 51) of the teachable and usable knowledge produced by our teaching and research systems?

At the core of these questions, we find the same calls for a réforme de l'entendement (Locke's "understanding", or Spinoza's "intellectus"), which invites us to reflect on our collective quest for a "new paradigm for 'lifelong' educational policies" (Ambrosio \& Lerbet-Sereni, 2006). Does this search not stem from the multiple perverse effects which we can now better identify - inherent to the two-way correspondence postulated by the Cartesian thought between the 'scientifically true' and the 'morally good'?

This scientistic (and post-scientistic) belief, whose arbitrary character is recognized again, was perhaps very comfortable, because it legitimized the resignation of the citizens: why asking ourselves whether something is or not morally good, when scientific experts have a Cartesian method that helps determining morally good behavior in a "very true and certain way because reason so determines" (Descartes, 1637 , p. 26, my translation)? ${ }^{13}$

An illusionary comfort for citizens who know today that they need to reverse the motto of the scientific experts who guarantee shamelessly: "the citizen is blind without the expert's glasses". From now on, we do not wish to submit ourselves anymore to this theo-scientism. We want and we can assume, with humility and pragmatism, our responsibilities in the development of this new reform of understanding. This reform that Morin proposes to call "reform of thought": "A way of thinking which is capable of establishing relationships and solidarities between disjointed knowledge is also capable of being prolonged in an ethics of reliance [capacity to establish relationships] and solidarity among humans" (Morin, 1999, p.111). What is at stake is the recognition of the fact that the "scientific expert is blind without the glasses of the citizen", a citizen that $\mathrm{s} /$ he is also; what increases even more the scientific expert's responsibility and awareness of the risks (and therefore uncertainty and unpredictability) of the fascinating adventure of knowledge, in which s/ he is involved on the front line.

We can no longer resign ourselves to such a simplistic image of human knowledge that reduces ethics to the epistemic. Knowledge alone cannot commands action. The pragmatic is not determined by the epistemic; the pragmatic is reflected by the epistemic,

\footnotetext{
${ }^{13}$ One should read again and meditate on the famous parable of the Cartesian discourse about a

"traveller lost in forest" from which this quote is taken.
} 
which, in its turn, is also teleologically reflected by the pragmatic. The scientistic paradigm was based on binary terms (epistemic and pragmatic ones) separating those who know from those who do, without an autonomous form of ethical questioning. The paradigm of complexity is ternary, continuously challenging everyone to unite pragmatics and ethics, through the mediation of the epistemic.

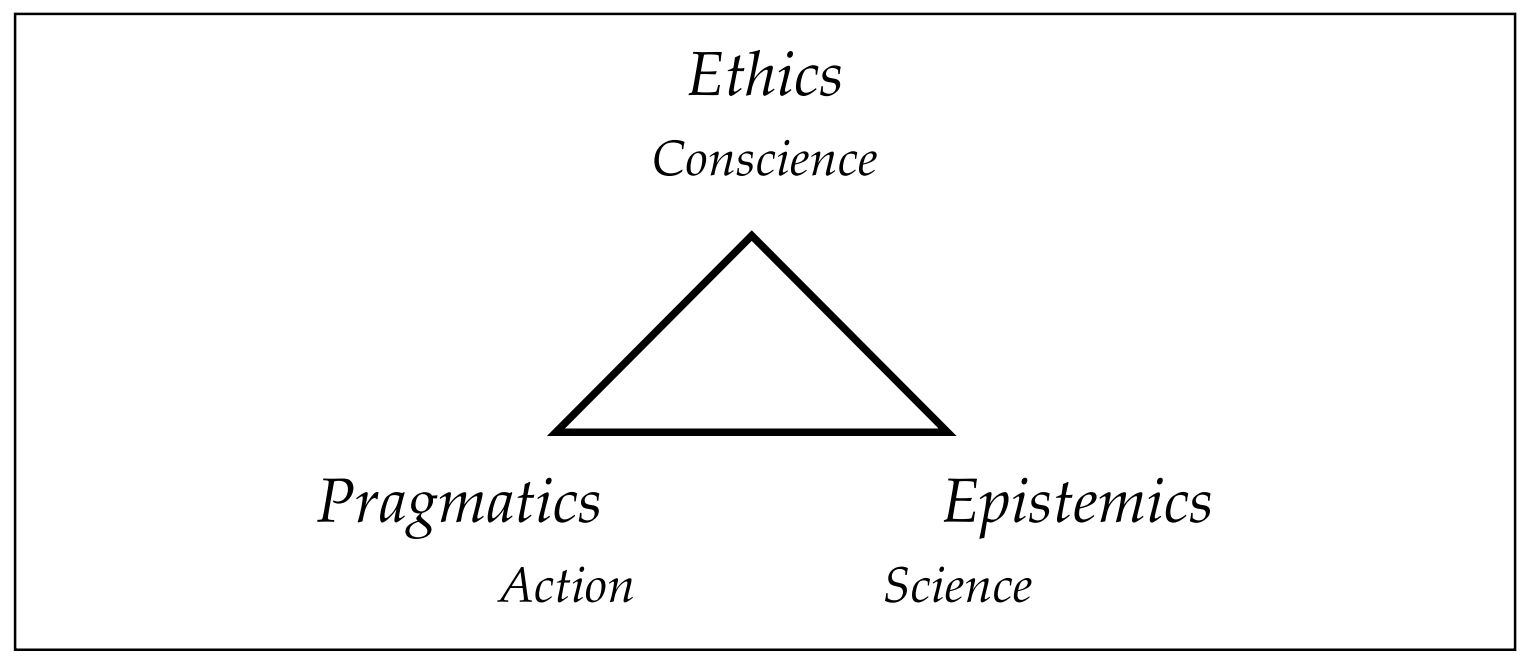

Here is an ethics with no other foundation than itself, though it requires external support: it needs to be fed by faith, to be backed up by an anthropology and to know the practical conditions and situations where it is applied ... It is an ethics of understanding $\ldots$ an ethics which is demanding from ourselves and indulgent towards others, not the reverse ... Ethics should mobilize intelligence in order to face the complexity of life, of the world, of ethics itself. (Morin, 1994, p. 126, my translation)

Morin likes to remind us of this conjunction of intelligence (let us then work on thinking well) and ethics (the principle of the moral): "The moral is a blaze that needs to be explained by intelligence and intelligence is a blaze that needs to be explained by the moral. Ethics should mobilize intelligence to face the complexity of life, of the world, of ethics itself" 14 (Morin, 1994, p. 136). But he invites us to understand it in its movement, in its dialogical action. "It is practiced" and thus we can interpret it as an ethics of understanding, which is recognized primarily through its capacity of working to understand the other: "An ethics which would enroll us in an earthly fraternity" (Morin, 1994, p. 126, my translation).

This courage of intelligence and this wish for lucidity, are they not what we recognize when we try to understand our own history? This mysterious and intelligible adventure, which bring us here and now to reflect together on the ethics of understanding in the planetary era? When the evidence of so many catastrophes (rather highlighted by the media than enlightening for our intelligence) incites us to a wise resignation, we are still persisting in transforming each one of our experiences in science with conscience. The intelligence of action enlightens conscience (ethics) and ethics enlightens the intelligence of action (understanding).

Thus, tenaciously and without hope of completion, we are trying to understand the human adventure through the adventure of knowledge. As early as 1932, Paul Valéry,

\footnotetext{
${ }^{14}$ See Morin's (2004) La Méthode (vol. 6) Ethique; in particular its excellent chapter 4, precisely titled "Ethique de la compréhension" (pp. 121-139), where the following conclusion can be read: "Understanding does not mean to understand everything, it also means to recognise that the ununderstandable also exists" (p. 139).
} 
who I believe was one of the most powerful epistemologists of the $20^{\text {th }}$ century, reminded us of this ethical demand of the epistemic asceticism ("the sharpness of the intellect") that gives a meaning to the extraordinary adventure of humanity still trying to civilize the Planet-Earth-Motherland.

We should keep in our minds and in our hearts the desire [volonté] for lucidity, the sharpness of the intellect, the feeling of greatness and risks, of the extraordinary adventure in which humanity [le genre humain] got involved, perhaps withdrawing from the initial and natural conditions of the human race, going who knows where!

(Valéry, 1932, p.1040, my translation)

Our ethical questions about the meaning and the legitimacy of each one of our acts, on the meaning of human action, in a world where everyone would like to be more and better civilized, bring us also to recognize the infinite spiral of complex ethics, which cannot be understood as long as it is dissociated from its active practice: how can it be enlightened and what does it enlighten?

Ethics is not separable from human experience, that it should enlighten, always inciting it to transform itself into science, and to transform this science so that it blends with its internal critic, being careful, in the first place, to doubt its own presumed objectivity and recognizing the teleological processes which form it. "Desire for lucidity", ethics expresses itself through our awareness of the epistemic limits of the science that clarifies ethics, and of the pragmatic outlines which ethics clarifies.

It is therefore necessary to understand, step by step, the intelligible and evolving complexity of this indivisible ternary loop, which connects in permanence action, reflection and meditation.

All come together: 'the three threads of an eternal garland' - pragmatics, epistemics, ethics. The experience of human action (ecology of action) is wisely and skillfully transformed in symbolized knowledge, a science that relies on self-criticism in order to organize itself teleologically and become moral awareness, which recursively reenlightens and potentially re-transforms the exercise of action and the perception of experience.

Did the action exist at the beginning (Goethe)? Or was it the verb (system of symbols)? Perhaps the answer is of no interest here since we understand both as an inseparable whole? Perception, sensation, emotion, memorization, are they not actions exercised irreversibly throughout time?

This loop that grounds the understanding of our relationship with the world and with ourselves describes our desire for lucidity, our refusal to be resigned to doing without understanding, since we know that to try to understand, it is necessary to do and that to do assuming the responsibility for our acts, it is necessary to try to understand. The intelligent action demands the recognition of the third included [tiers inclus] in the relation between action and reflection, between experience and knowledge, between pragmatiké and epistémè. Ethics is that teleological crucible that we have to consciously consider, in order for the experience enlightened by ethics to transform into new knowledge, which transforms the knowledge that created it.

\section{A huge epistemological revolution... our future is gifted with essential unpredictability}

Our meditations on the exercise of the ingenium - this strange faculty of the human mind - that our lifelong learning educational systems can promote, look like historical considerations. However, are they not truly up-to-date when we explore any study methods of our time, at the beginning of the $21^{\text {st }}$ century? The experience of disegno - or systemic modeling - and that of ingegno - or pragmatic intelligence - invite us to try to finally bring together our means of investigation and action with our means of representation 
and understanding. Should we resign ourselves to that terrible diagnosis formulated by Valéry (1948/1993, p. 41)? "Our future is gifted with essential unpredictability [imprévisibilité] ... it is the only forecast we can make... our means of research and action leave our means of representation and understanding well behind".

We are not unarmed. We can develop our understanding, our capacity to understand, our aptitude to represent ourselves intelligibly, under different points of view, the situations we face and which we also transform. At stake is mapping out the way (Avenier, 1992), which means to develop strategies of elaboration and representation of actions that might as well be informants, capable of generating at least one possible sense for behavior. Edgar Morin often recalls:

Complexity calls for strategy. Strategy is all that is left in order to progress through uncertainty and randomness...The method of complexity requires us... - to think without ever closing concepts ...- to re-establish the links between what is disjointed ... - to think with singularity, locality, temporality..." (Morin, 1991, my translation)

And since complexity calls for strategy, the study methods for the present time will then be a strategy, a unifying and not sectioning exercise of our ingenium.

I have never believed in 'explanations' [stressed by Valéry] but I believed that it was necessary to look for 'representations' (or disegno) on which one could work, as if we were working on a map, or as an engineer would work on a project, etc. (or ingegno) and which might be of help for action. (Valéry, 1942/1987, pp. 99-100, my translation)

Therefore, the method will primarily privilege representation or modeling - "disegno" a construction of symbolic representations of problems perceived as actions and through actions. We only reason on models. Is it not necessary to first give form to such contextualizing models?

It will also be interpretation, argumentation or critical and teleological judgment, or simulation, heuristic conceptions of possible solutions - "ingegno" - an exercise of reflective or deliberating reason, rather than just determining reason. Heinz von Foerster used to ask: "can we not hold on to reasoning in terms of 'in order to' rather than in terms of 'because' when we want to answer the question 'why...?' which could then be formulated as 'what for...?'" (Segal, 1990).

Since the field has widened, the relevance of the question 'why not?' becomes legitimate. Why should scientific knowledge avoid or reject it? "There are those who see things as they are and ask why, there are those who imagine things as they could be and say...'why not?" (Shaw, quoted in De Coninck, 2006, p. 25, my translation)

Five centuries after Leonardo da Vinci invented the helicopter, Bachelard invited us to accept the challenge: "we will show that, in scientific philosophy, after the old philosophy privileging the 'as if', comes the philosophy privileging the 'why not'... In the world of thought [as] in the world of action... [one can make] reason proceed from 'why' to 'why not'" (Bachelard, 1934, pp. 10-11, my translation).

The recognition of our human freedom capable of exploring with intelligence the field of possibilities incites us then to an ascetic effort aiming for the sharpness of the intellect. The more the field of possibilities broadens, the more the field of ethically unacceptable possibilities broadens. We cannot hide behind the scientific experts to diagnose the morally good under the cloak of presumable scientific truth. We should assume our solidarizing responsibility as "citizens of Mother Earth". "Ethics should mobilize intelligence in order to cope with the complexity of life, of the world and ethics itself." (Morin, 1994, p. 136, my translation).

All we have is this weapon, the intelligence of complexity, the ingenium, but it is so precious that we should maintain it with passion, step by step, pragmatically, requiring ourselves to always deliberate, facing up uncertainty and contradiction and being therefore capable of exercising the human capacity of consciously elaborating our future behavior. 
Human action requires ethics, which requires epistemology, which calls for action... Is this not what Pascal invited us to meditate on the parable of the thinking reed?

Man is only a reed, nature's weakest, but he is a thinking reed... Our whole dignity remains therefore in the thought. It is from there that we should raise ourselves and not from space or time that we would not know how to fill. Let us then work hard on thinking well: here is the principle of moral. (Pascal, 1963, pp. 200-347, my translation)

Is this not what we understand when we exercise our 'intelligence of complexity' in the situations in which we intervene? It is always transforming our experiences in science with conscience without ever separating pragmatics, ethics, and epistemics: "Let us then work hard on thinking well" (ibid.)

Let us then borrow from Leonardo da Vinci's method one of its mottos that serves as viaticum to humbly re-elaborate a study method for the present time: "A sacred furor of doing in order to understand and understanding in order to do, which transcends any philosophy."(Valery, 1948/1993)

\section{References}

Ambrósio, T., \& Lerbet-Sereni, F. (2006). Chemins de formation: Inscrire dans la société les chemins de l'autoorganisation, de l'autonomie et de l'identité. In T. Ambrósio, \& F. Lerbet-Sereni (Eds.) Les sciences de l'éducation à la croisée des chemins de l'auto organisation (pp. 185-203). Paris: L'Harmattan.

Arnaud, A., \& Nicole, P. (1684/1992). La logique ou l'art de penser. Paris : Gallimard.

Avenier, M.J. (dir.) (1992). La stratégie, chemin faisant. Paris : Economica.

Bachelard, G. (1934). Le nouvel esprit scientifique, Paris: PUF.

Bachelard, G. (1938). La formation de l'esprit scientifique. Paris: Vrin.

Bacon, F. (1620). The new organon. Basbous, K. (2005). Avant l'œuvre, essai sur l'invention architecturale. Paris: Les éditions de l'Imprimeur.

Bacon, F. (2008). CEuvres philosophiques, morales et politiques de François Bacon. Paris : Archives Karéline Editions.

Basbous, K. (2005). Avant l'euvre, essai sur l'invention architecturale. Paris: Les Editions de l'Imprimeur.

Bogdanov, A. (1981). Essays in Tektology. (trans. G. Gorelik). Seaside, CA: Inter System Publications.

Boole, G. (1854/2005). An investigation of the Laws of Thought. Electronic version available at: http: / / www.gutenberg.org/ files/15114/15114-pdf.pdf

Centre National de la Recherche Scientifique. (2002) CNRS strategic scheme. Available at http:/ / www.cnrs.fr/ strategie/index.htm (February $15^{\text {th }}, 2007$ )

Calvino, I. (1985). Le modèle des modèles rêvé par Palomar. In Palomar (chap. 323). Paris: Seuil.

Ciaravino, I. (1987). Traité de la peinture (trans. A. Chastel). Paris: Berger-Levault.

Ciaravino, J. (2004). Un art paradoxal. La notion de disegno en Italie (XV $V^{\text {eme }}-X V I^{\text {èm }}$ siècles). Paris: L'Harmattan.

Comte, A. (1852/1964). Catéchisme positiviste. Paris: Flammarion.

De Coninck, P. (2006). Design et complexité: les leçons d'une experience d'enseignement. In P. Boudon (Ed.) Conceptions. Epistémologie et poïétique (pp. 25-42). Paris: L'Harmattan.

Descartes, R. (1637). Discours de la méthode. Original edition available at: http: / www.acgrenoble.fr/PhiloSophie/file/descartes_methode.pdf.

Floris, E. (1974). "Une culture de l'imagination" La rupture cartésienne et la naissance d'une philosophie de la culture dans les œuvres juvéniles de J.-B. Vico. Available at http: / / alain.auger.free.fr/t313040.htm

Lerbet-Sereni, F. (2004). Expériences de la modélisation et modélisation de l'expérience. Paris: L'Harmattan.

Luglio, D. 2003. La nouvelle science. Connaissance, rhétorique et science dans l'cuvre de G. Vico. Paris: PUF.

Morin, E. (1977/1992). Method (vol. 1) The nature of nature (trans. J.L.R. Bélanger). New York: Peter Lang.

Morin, E. (1977-2004 / 2008). La méthode [new edition including the six volumes published between 1977 and 2004]. Paris: Seuil

Morin, E. (with M. Ceruti and G. Bocchi) (1991). Un nouveau commencement. Paris: Seuil.

Morin, E. (1994). Mes démons. Paris: Stock.

Morin, E. (1997). Amour, poésie, sagesse. Paris: Seuil.

Morin, E. (1999). La tête bien faite. Repenser la réforme - Réformer la pensée. Paris: Seuil.

Morin, E. (2004). La Méthode (vol. 6). Ethique. Paris: Seuil. 
Pascal, B. (1963). Pensées. Paris: Seuil.

Piaget, J. (1967). Logique et connaissance scientifique. Paris : Gallimard.

Pons, A. (2005). Notes introductives. In G. Vico (1708/2005). La méthode des études de notre temps (trans.

A. Pons). Paris: Grasset. Electronic version available at :

http: / / www.intelligence-complexite.org/docs/conseilscient/0511vico_pons.pdf

Segal, L. (1990). Le rêve de la réalité: Heinz von Foerster et le constructivisme. Paris: Seuil

Simon, H.A., \& Kaplan, C.A. (1989). Foundations of cognitive science. In M. Posner (Ed.), Foundations of cognitive science (pp. 1-47). Cambridge, MA: MIT Press.

Valéry, P. (1894/1919). Introduction à la méthode de Léonard de Vinci. Paris: Editions de la Nouvelle Revue Française. Available at: http: / / ia700409.us.archive.org/17/items / introductionla00valuoft/introductionla00valuoft.pdf

Valéry, P. (1932). La politique de l'esprit, notre souverain bien. Paris: La Pléiade.

Valéry, P. (1942(1987). Cahiers 1894-1914. Paris: Gallimard.

Valéry, P. (1948/1993). Vues. Paris: Editions de la Table Ronde.

Vico, G. (1708/2005). La méthode des études de notre temps (trans. A. Pons). Paris: Grasset. Electronic version available at :

http: / / www.intelligence-complexite.org/docs/ conseilscient/0511vico_pons.pdf

Vico, G. (1710/1993). De l'antique sagesse de l'Italie (trans. J. Michelet). Paris: Flammarion.

Vico, G. (1744/1997). Principj di scienza nuova. Available at: http:/ / www.pannunzioal.it/biblioteca/opere/P/principi_scienza_nuova.pdf

Vico, G. (1974). "Une culture de l'imagination". In E. Floris, "Une culture de l'imagination" La rupture cartésienne et la naissance d'une philosophie de la culture dans les cuvres juvéniles de J.-B. Vico. Available at http: / / alain.auger.free.fr/t313040.htm

\section{Acknowledgments}

This paper is based on a communication originally presented in French at the Faculty of Psychology and Educational Sciences of the University of Lisbon (Portugal) on February 15 ${ }^{\text {th }}, 2007$ and later published in the journal Sísifo - Educational Sciences Journal, ${ }^{\circ} 4$ (http:/ / sisifo.fpce.ul.pt) with the title: "The Intelligence of Complexity: Do the ethical aims of research and intervention in education and training not lead us to a "new discourse in the study method of our time"?" The original translation from Filomena Matos was later edited by Complicity's editorial team. The editors would like to thank the author, Jean-Louis Le Moigne, and Rui Canário, Managing Editor of Sisifo, for granting permission to Complicity to republish this paper.

\section{About the Author}

Jean-Louis Le Moigne (born in 1931) is Professor Emeritus at the Université d'Aix-Marseille, France. Trained as an engineer (Ecole Centrale de Paris), he worked in an industrial firm for 15 years (R\&D, Operations Research, Central Planning, Logistics), before a sabbatical year in 1970-71 (Harvard Business School \& Sloan School, MIT). Since 1971, he worked as a professor at the University of Aix Marseille, teaching and researching in the many fields of Systems Sciences and Artificial Sciences. He is still challenging their epistemological foundations in order to legitimize the "actionable knowledge" that these new sciences are supposed to produce. Le Moigne is the Coordinator of the Network Intelligence de la complexité (MCX-APC) (www.intelligence-complexite.org), President of the European Programme Modélisation de la Complexité (AE-MCX), and Vice President of the Association pour la Pensée Complexe $(A P C)$. More information and references are available at: http://www.intelligencecomplexite.org/fr/pages-speciales/bio-bibliographie-de-jean-louis-le-moigne.html

E-mail: jl.le-moigne@univ-amu.fr

(c) Copyright 2013. The author, JEAN-LOUIS LE MOIGNE, assigns to the University of Alberta and other educational and nonprofit institutions a non-exclusive license to use this document for personal use and in courses of instruction provided that the article is used in full and this copyright statement is reproduced. The author also grants a non-exclusive license to the University of Alberta to publish this document in full on the World Wide Web, and for the document to be published on mirrors on the World Wide Web. Any other usage is prohibited without the express permission of the authors. 